\title{
In-vitro antibacterial activity of garlic cloves and ginger rhizomes on food-borne pathogens
}

\author{
Ogodo A.C.*, Ekeleme U.G \\ Department of microbiology, Abia State University, P.M.B. 2000, Uturu Abia State Nigeria \\ *Corresponding author E-mail: alloysiuschibuike@yahoo.com
}

\begin{abstract}
The antibacterial activity of ginger (Zingiber officinale) and garlic (Allium sativum) extracts was investigated on selected food borne pathogens using Agar well diffusion method. The organisms are Escherichia coli, Staphylococcus aureus, Salmonella species and Bacillus cereus. Two different extracts (cold water and ethanol) were obtained from the garlic bulbs and ginger rhizomes. The results indicated that the different bacteria species demonstrated different levels of sensitivity to the extracts. The cold water extract of the ginger produced maximum activity against Salmonella species $(13.10 \mathrm{~mm})$, Staphylococcus aureus $(9.67 \mathrm{~mm})$, Bacillus cereus $(6.67 \mathrm{~mm})$ and no inhibition on Escherichia coli $(0.0 \mathrm{~mm})$. The ethanolic extract produced maximum activity against Staphylococcus aureus (13.05mm), Salmonella species $(10.09 \mathrm{~mm})$ and no inhibition on Escherichia coli $(0.0 \mathrm{~mm})$ and Bacillus cereus $(0.0 \mathrm{~mm})$. The extracts of garlic (cold water and ethanolic) produced the maximum inhibitory effect towards Staphylococcus aureus $(38.67 \mathrm{~mm}$ and $31.00 \mathrm{~mm})$, Bacillus cereus $(36.67 \mathrm{~mm}$ and $30.21 \mathrm{~mm})$ respectively. The cold water extract produced an inhibition of $26.00 \mathrm{~mm}$ on E. coli and $27.33 \mathrm{~mm}$ on Salmonella species while the ethanolic extract on E. coli (20.10mm) and Salmonella species $(19.32 \mathrm{~mm})$. The minimum inhibitory concentration (MIC) of cold water and ethanol extracts of ginger were respectively $75 \%$ and $50 \%$ (S. aureus), $50 \%$ and $25 \%$ (Salmonella species), $100 \%$ and resistant (B. cereus) while E. coli was resistant to both extracts. The MIC (\%) of the cold water and ethanol extract of garlic were respectively $25 \%$ and $75 \%$ (B. cereus), $25 \%$ and $50 \%$ (S. aureus) and $75 \%$ for both extracts on E. coli and Salmonella species respectively. The result revealed that garlic extracts were more effective against the test organisms than ginger extracts. However both plants can serve as potential inhibitors of food pathogens and can increase the shelf life of foods if properly incorporated.
\end{abstract}

Keywords: Antibacterial activity, ginger, garlic, food-borne pathogens, inhibition.

\section{Introduction}

Herbs and spices parts of plants from indigenous or exotic origin are essential part of human diet as they improve taste, color and aroma of foods [1], [2]. In addition they act as preservatives in many foods; they also have antioxidant [3] and antimicrobial properties [4]. Herbs have also been utilized in human and veterinary medicine [5].

Ginger (Zingiber officinale Roscoe, Zingiberacae) is widely used around the world as herbs and as spices in foods especially in the East. It is a member of the family Zinberaceae and its scientific name is Zingiber officinale [3]. Ginger is thick scaly rhizomes which are aromatic, thick lobed, branched, have a scaly structure and they possess a spicy lemon like scent. The rhizomes contain both aromatic and pungent components [4]. For centuries, it has been an important ingredient in Chinese, Ayurvedic and Tibb-Unani herbal medicines for the treatment of catarrh, rheumatism, nervous diseases, gingivitis, toothache, asthma, stroke, constipation and diabetes [6], [7], [8]. Several reviews have appeared in the literature about this plant, and this may reflect the popularity of the subject and its common use as a spice and a medicinal plant [9], [10].

Garlic belongs to a family of Alliaceae and its scientific name is Allium sativum. Other members of the family include onion, leek, shallot and leek. Garlic is widely used in culinary and medicine [3]. It has a pungent hot flavor but mellows and improves with cooking. It has been utilized to fight infections such as cold, cough, asthma, diarrhea, flu, headache, sore throat, abdominal discomfort and respiratory tract infections [11], [12].

The antibacterial properties of crushed garlic have been known for a long time. Various garlic preparations have been shown to exhibit a wide spectrum of antibacterial activity against Gram-negative and Gram-positive bacteria including species of Escherichia, Salmonella, Staphylococcus, Streptococcus, Klebsiella, Proteus, Bacillus, and Clostridium. Even 
acid-fast bacteria such as Mycobacterium tuberculosis are sensitive to garlic. Analysis of steam distillations of crushed garlic cloves performed over a century ago showed a variety of allyl Sulfides which are isolated and identified as the component responsible for the remarkable antibacterial activity of crushed garlic cloves. The compound turned out to be an oxygenated sulfur compound which they termed allicin from the Latin name of the garlic plant, Allium sativum [13], [14].

Food-borne pathogens are widely distributed in the environment and may be a significant cause of mortality and morbidity in the population [15]. Escherichia coli (EHEC), is a significant food borne hazard in many countries around the world. Infection often causes haemorrhagic diarrhoea, and occasionally to kidney failure and death. Salmonella is another bacterium that is the cause of food borne illness mainly from foods of animal origin throughout the world. Staphylococcus aureus and Bacillus cereus causes food borne illness due to their ability to form heat stable toxins [16]. Hence, this work aimed at evaluating the in-vitro antibacterial activity of the widely used spices, garlic cloves and ginger rhizomes extracts on these food-borne pathogens, Escherichia coli, Staphylococcus aureus, Salmonella sp. and Bacillus cereus.

\section{Materials and methods}

\subsection{Sources of materials}

The fresh forms of Zingiber officinale (ginger rhizomes) and Allium sativum (Garlic bulbs) were purchased from Eke Okigwe market, Imo State Nigeria. The test organisms used in this research consisted of two Gram-positive and two Gram-negative bacteria isolates obtained from the Department of Microbiology, Abia State University, Uturu. Microorganisms used to assess the antimicrobial properties of the plants extracts were Escherichia coli, Staphylococcus aureus, Salmonella species and Bacillus cereus. The test organisms were cultured on agar slants and stored in the refrigerator at $4^{\circ} \mathrm{C}$. Subcultures were made at two-week intervals.

\subsection{Preparation of cold water extract of zingiber officinale and allium sativum}

The method of [17] was adopted for the extraction of the plant. This was carried out by measuring $20 \mathrm{~g}$ of each of fine grounded powder of rhizome of Zingiber officinale and Allium sativum on an electronic weighing balance. This was dispensed into two beakers, each containing $100 \mathrm{ml}$ of distilled water. These were soaked for 48hours after which the solution was carefully filtered with muslin cloth into a sterilized conical flask of $100 \mathrm{ml}$ and the filtrates obtained were stored in the refrigerator at a temperature of $4^{\circ} \mathrm{C}$ until required.

\subsection{Preparation of ethanol extract of zingiber officinale and allium sativum}

This also followed the method in 2.2 above. Twenty grammes of each fine grounded powder of Zingiber officinale and Allium sativum were dispensed into a beaker containing $100 \mathrm{ml}$ of $70 \%$ ethanol respectively. They were soaked for 48hours while the resulting supernatant was decanted into a conical flask of $100 \mathrm{ml}$ and kept in the refrigerator for further study. The extraction of the plants was carried out according to the method of [17].

\subsection{Sterility test of the extracts}

Each of the above extracts (Aqueous extract and Ethanolic extract) was tested for contaminants. This was carried out by inoculating them on nutrient agar and incubation at 370C for 24 hours. The plates were observed for growth. No growth in the extracts after incubation indicated that the extracts are sterile. The extracts were then assessed for antibacterial activity [18].

\subsection{Antibacterial tests of zingiber officinale and allium sativum extracts}

The agar diffusion method of [17] was used from the $48 \mathrm{~h}$ old cultures of the test organisms with the aid of sterile syringes. $0.5 \mathrm{ml}$ of each of the test organisms was inoculated into different sterile Petri dishes. About 20ml of sterile media was aseptically poured into each dish. The dishes were gently rocked for proper mixture and the nutrient agar was allowed to solidify. Afterwards, wells were dug in the plates with the aid of a sterilized cork borer of $6 \mathrm{~mm}$ diameter. Wells were bored on each plate and were filled with a particular extract. They were allowed to stand for one hour for proper diffusion; selected solvent of extraction was used as negative control. The efficacy of extracts against bacteria was compared with the broad spectrum antibiotic Ciprofloxacin (positive control). The plates were incubated at $370 \mathrm{C}$ for $24 \mathrm{hrs}$ in an incubator and the diameter of the zones of inhibition was measured in millimeter. Each sample 
was assayed in triplicate and the mean values were observed. The antibacterial activity was interpreted from the size of the diameter of zone of inhibition measured to the nearest millimeter $(\mathrm{mm})$ as observed from the clear zones surrounding the wells.

\subsection{Determination of minimum inhibitory concentrations (MICS)}

The MIC of the extracts (Aqueous and Ethanol) was performed by agar well diffusion method for all selected test pathogens. Concentration of 100, 75, 50, 25, 12.5 of the extracts (Hot water and ethanol) were prepared separately and dissolved in $1 \mathrm{ml}$ of fresh water and ethanol. The MIC of the extracts for the test micro-organisms were regarded as the lowest concentration that inhibited visible growth of the test organisms on the agar plate after $24 \mathrm{hrs}$ incubation at $370 \mathrm{C}$.

\section{Results}

The results of the antibacterial activity of ginger (Zingiber officinale) and garlic (Allium sativum) extracts indicated that different bacterial species demonstrated different levels of sensitivity towards the tested samples of ginger and garlic extracts. The diameter for zone of inhibition for ginger extracts was lower than that of garlic for the corresponding concentrations. The cold water extract of the ginger produced maximum activity against Salmonella species (13.10mm), Staphylococcus aureus $(9.67 \mathrm{~mm})$, Bacillus cereus $(6.67 \mathrm{~mm})$ and no inhibition on Escherichia coli $(0.0 \mathrm{~mm})$. The ethanolic extract of ginger produced maximum activity against Staphylococcus aureus (13.05mm), Salmonella species $(10.09 \mathrm{~mm})$ and no inhibition on Escherichia coli $(0.0 \mathrm{~mm})$ and Bacillus cereus $(0.0 \mathrm{~mm})$ (Table 1$)$.

Fig. 1. Showed the mean zones of inhibition following exposure of test bacteria to extracts of Zingiber officinale (Ginger rhizomes) and Ciprofloxacin.

The extracts of garlic (cold water and ethanolic) produced the maximum inhibitory effect towards Staphylococcus aureus $(38.67 \mathrm{~mm}$ and $31.00 \mathrm{~mm})$, Bacillus cereus $(36.67 \mathrm{~mm}$ and $30.21 \mathrm{~mm}$ ) respectively. The cold water extract produced an inhibition of $26.00 \mathrm{~mm}$ on E. coli and $27.33 \mathrm{~mm}$ on Salmonella species while the ethanolic extract on E. coli $(20.10 \mathrm{~mm})$ and Salmonella species $(19.32 \mathrm{~mm})$ (Table 2). Fig. 2 showed mean zones of inhibition following exposure of test bacteria to extracts of Allium sativum (Garlic bulbs) and Ciprofloxacin.

Table 3 represented the minimum inhibitory concentration $(\%)$ of cold water extract of ginger. The results showed that $75 \%$ was the least concentration for S. aureus, $50 \%$ for Salmonella species, $100 \%$ for B. cereus and no inhibition was produced on E. coli.

Table 4 showed the MIC (\%) of the ethanolic extract of ginger. 50\% was the least concentration for S. aureus, $25 \%$ for Salmonella species, while E. coli and B. cereus were resistant to the highest concentration used (100\%). The minimum inhibitory value of cold water extract of garlic against the Gram negative bacteria (E. coli and Salmonella species) was $75 \%$, while the Gram positive bacteria (S. aureus) was $25 \%$ as shown in Table 5.

Table 6 showed the MIC (\%) of the ethanolic extract of garlic, 75\% was the least concentration for E. coli, Salmonella species and B. cereus while $50 \%$ was the least concentration for S. aureus.

Table 1: Antimicrobial susceptibility pattern of extracts of zingiber officinale (ginger rhizomes)

\begin{tabular}{lccc}
\hline \multirow{2}{*}{ Organisms } & \multicolumn{3}{c}{ Diameters of the inhibition zone (mm) } \\
\cline { 2 - 4 } & Cold water extract & Ethanolic extract & Ciprofloxacin \\
\hline E. coli & 0.00 & 0.00 & $37.00 \pm 1.73$ \\
S. aureus & $9.67 \pm 0.57$ & $13.05 \pm 0.52$ & $26.67 \pm 1.15$ \\
Salmonella species & $13.10 \pm 0.52$ & $10.09 \pm 0.53$ & $34.33 \pm 2.88$ \\
Bacillus cereus & $6.67 \pm 0.57$ & $10.09 \pm 0.53$ & $26.67 \pm 1.52$ \\
\hline
\end{tabular}

Table 2: Antimicrobial susceptibility pattern of extracts of allium sativum (garlic bulb)

\begin{tabular}{|c|c|c|c|}
\hline \multirow[t]{2}{*}{ Organisms } & \multicolumn{3}{|c|}{ Diameters of the inhibition zone (mm) } \\
\hline & Cold water extract & Ethanolic extract & Ciprofloxacin \\
\hline E. coli & $26.00 \pm 0.57$ & $20.10 \pm 1.12$ & $37.00 \pm 1.73$ \\
\hline S. aureus & $38.67 \pm 0.57$ & $31.00 \pm 0.59$ & $26.67 \pm 1.15$ \\
\hline Salmonella species & $27.33 \pm 0.57$ & $19.32 \pm 1.52$ & $34.33 \pm 2.88$ \\
\hline Bacillus cereus & $36.67 \pm 0.52$ & $30.21 \pm 0.58$ & $26.67 \pm 1.52$ \\
\hline
\end{tabular}




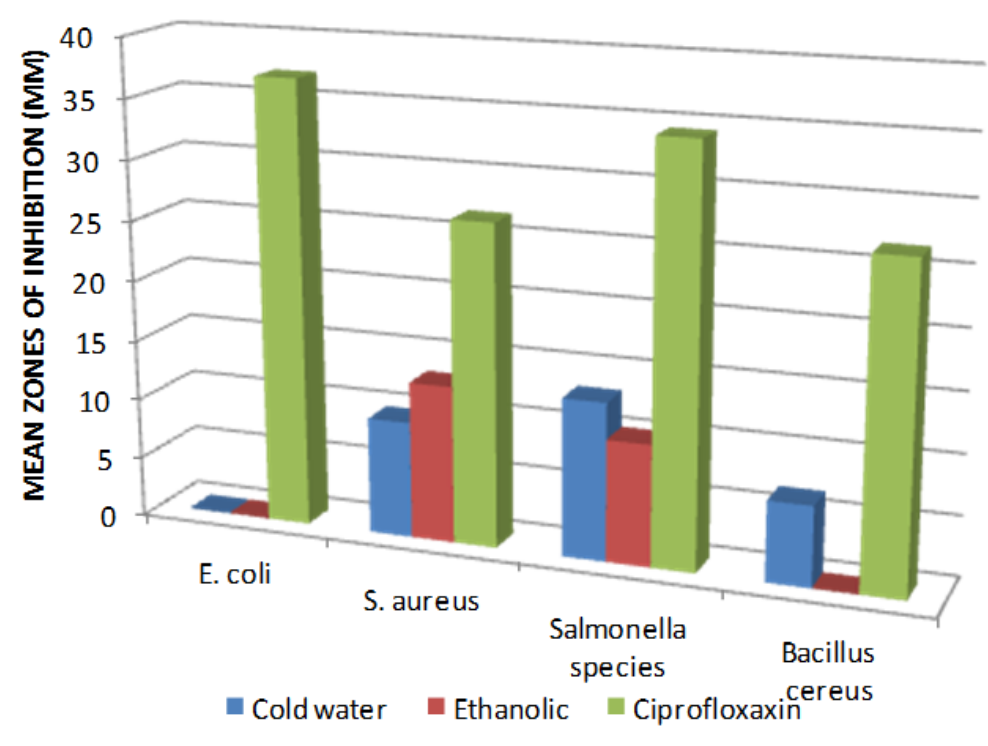

Fig. 1: Mean zones of inhibition following exposure of test bacteria to extracts of zingiber officinale (ginger rhizomes) and ciprofloxacin

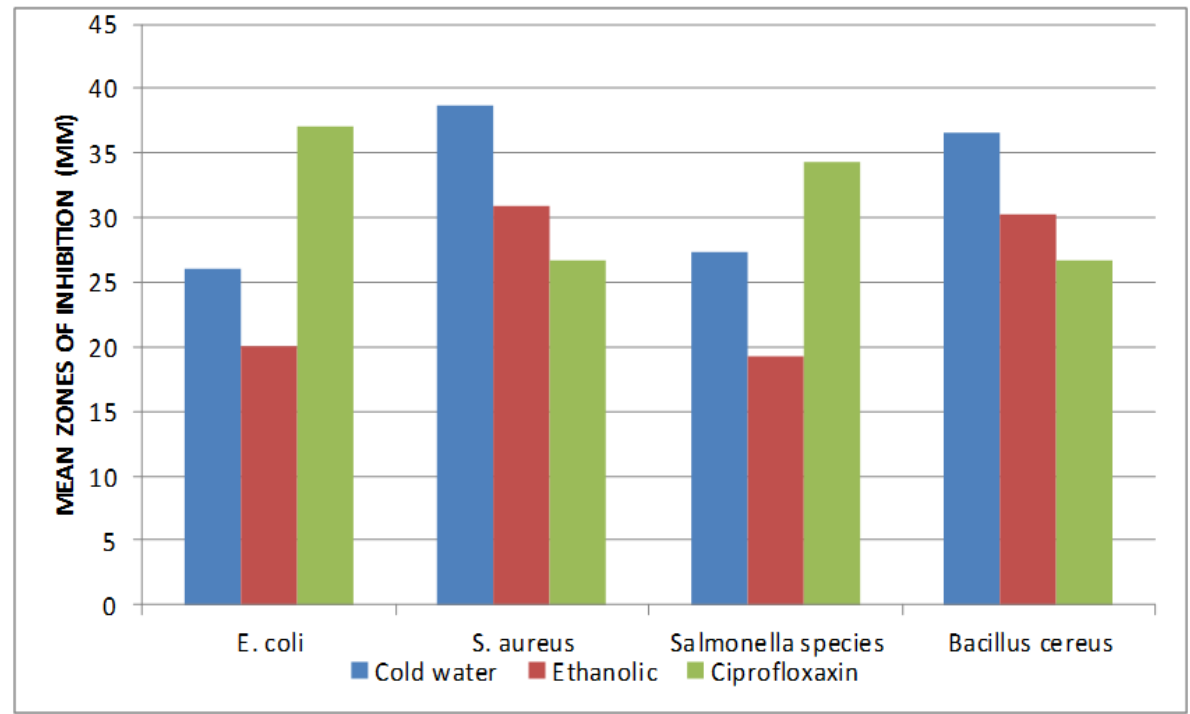

Fig. 2: Mean zones of inhibition following exposure of test bacteria to extracts of allium sativum (garlic bulbs) and ciprofloxacin.

Table 3: Determination of minimum inhibitory concentration (MIC) value of cold water extract of zingiber officinale against tested organisms.

\begin{tabular}{ccccc}
\hline & \multicolumn{3}{c}{ Test organisms } \\
\cline { 2 - 5 } Concentration (\%) & E. coli & S. aureus & Salmonella sp. & B. cereus \\
\hline 100 & + & - & - & - \\
75 & + & - & - & + \\
50 & + & + & + & + \\
25 & + & + & + & + \\
12.5 & + & + & +
\end{tabular}

$(-)=$ Absence of growth, $(+)=$ Presence of growth

Table 4: Determination of minimum inhibitory concentration (MIC) value of ethanolic extract of zingiber officinale against tested organisms.

\begin{tabular}{ccccc}
\hline & \multicolumn{4}{c}{ Test organisms } \\
\cline { 2 - 5 } Concentration $(\%)$ & E. coli & S. aureus & Salmonella sp. & B. cereus \\
\hline 100 & + & - & - & + \\
75 & + & - & - & + \\
25 & + & - & - & + \\
12.5 & + & + & + & + \\
\hline
\end{tabular}


Table 5: Determination of minimum inhibitory concentration (MIC) value of cold water extract of allium sativum against tested organisms.

\begin{tabular}{|c|c|c|c|c|}
\hline \multirow[b]{2}{*}{ Concentration (\%) } & \multicolumn{4}{|c|}{ Test organisms } \\
\hline & E. coli & S. aureus & Salmonella sp. & B. cereus \\
\hline 100 & - & - & - & - \\
\hline 75 & - & - & - & - \\
\hline 50 & - & - & - & - \\
\hline 25 & + & - & + & - \\
\hline 12.5 & + & + & + & + \\
\hline
\end{tabular}

Table 6: Determination of minimum inhibitory concentration (MIC) value of ethanolic extract of allium sativum against tested organisms.

\begin{tabular}{ccccc}
\hline & \multicolumn{4}{c}{ Test organisms } \\
\cline { 2 - 5 } Concentration $(\%)$ & E. coli & S. aureus & Salmonella sp. \\
\hline 100 & - & - & - & - \\
75 & - & - & + & B. cereus \\
50 & + & + & + \\
25 & + & + & + \\
12.5 & + & + & + \\
\hline
\end{tabular}

\section{Discussion}

Allicin has been found to be the active ingredient in garlic and it works as an antimicrobial agent by inhibiting DNA and protein synthesis moderately and inhibiting RNA synthesis completely as a primary target [12], [13]. Garlic is also rich in anionic components such as nitrates, chlorides and sulfates and other water soluble components found in plants and these components may have antimicrobial properties [12]. Previous authors have described the antibacterial activity of garlic extract against microorganisms. Bulbs belonging to the Allium genus had the most antibacterial activity against Streptococcus mutans [19] and against Streptococcus agalactiae [5]. In addition, garlic was shown to have antimicrobial activity against Streptococcus olaris, Streptococcus mitis, Staphylococcus aureus [20], [21]; Escherichia coli, Salmonella typhi, Shigella flexineri, Proteus mirabilis [12]; and Vibrio parahaemolyticus, Escherichia coli and Staphylococcus aureus [22]. Few studies have shown some bacteria to be resistant towards garlic extract and these include Escherichia coli and Staphylococcus aureus [23]. In ginger, the gingerol related components have been found to have antimicrobial activities [13]. There are several reports of the inhibitory effect of ginger in the form of extract against several bacteria [24], [25], [26]. Moderate to good antimicrobial properties of ginger were shown in previous studies [4], [2], [27]. Ginger has been reported to decrease 3 log cycles of the microorganisms in beef sausages after two to three months of frozen storage when used as an antimicrobial agent at the concentration of $1 \%$ [28]. However, some studies have reported as ginger having weak antimicrobial effects [15], [20], [23], [29] and it compares well with this study where E. coli and Salmonella typhi were resistant towards all ginger extract samples. Similar results were reported where ginger did not show any antibacterial activity against the multidrug resistant bacteria viz: Escherichia coli, Pseudomonas aeruginosa, Staphylococcus aureus, Salmonella Typhi [30]. Study by [22] also showed no antibacterial activity of ginger to Vibrio parahaemolyticus, Escherichia coli and Staphylococcus aureus.

In the current study, water and ethanol were utilized to prepare the extracts of ginger and garlic with various corresponding concentrations. The water extracts showed larger inhibitory zones for the bacteria tested than the ethanolic extracts, this could be that water liberated more the active organic compounds than the ethanol. In support, water extracts of garlic and ginger were reported to be more potent than ethanol and chloroform extracts against the tested microbes in a study [11]. Once again, the zones of inhibition of the garlic extracts were higher than that of the ginger extracts for the corresponding concentrations. The diameter for zone of inhibition for garlic water extract ranged from $38.67 \pm 0.57$ to $26.00 \pm 0.57$ at various concentrations used and the ethanolic extract had lower inhibition ranged from $31.00 \pm 0.59$ to $19.32 \pm 1.52$. The ginger water extract had lower zone of inhibition which ranged from $13.10 \pm 0.52$ to no inhibition in E. coli while the ethanolic extract of ginger had no effect on E. coli and B. cereus respectively.

\section{Conclusion}

Garlic can be utilized for the development of broad spectrum antibiotics as it has wide spectrum antibacterial activity. It can also be used as a potential inhibitor of food pathogens and prevent food poisoning. Shelf life of processed foods could be increased if garlic is used in the preservation of foods. In comparison, ginger has weaker antibacterial and may 
be used along with garlic as an antibacterial agent. However, further studies needs to be conducted to determine if better antibacterial activity is achieved by combining the two spices.

\section{References}

[1] E.L. de-Souza, T.L. Stamford, E.D. Lima, V.N. Trajano, J.M. Filho, Antimicrobial effectiveness of spices: approach for use in food. Brazilian Archives of Biology and Technology International Journal, 48 (2005), 549-558.

[2] A. Venugopal, S. Dasani, S. Rai, Antibacterial effect of herbs and spices extract on Escherichia coli. Electronic Journal of Biology, 5 (2009), 40-44.

[3] P. Karappiah, S. Rajaram, Antibacterial effect of Allium sativum cloves and Zingiber officinale rhizomes against clinical pathogens. Asia Pacific Journal of Tropical Biomedicine, 2 (2012), 597 - 601.

[4] G. Singh, I. Kapoor, P. Singh, C.S. De-Heluani, M.P. De-Lampasona, C.A. Catalan, Chemistry, antioxidant and antimicrobial investigations on essential oil and oleoresins of Zingiber officinale. Food and Chemical Toxicology, 46 (2008), 3295-3302.

[5] M. Alsaid, H. Daud, S.K. Bejo, A. Abuseliana, Antibacterial activities of some culinary spice extracts against Streptococcus agalactiac and its prophylactic used to prevent streptococcal infection in red hybrid Tilapia (oreochromis sp.). World Journal of Fish and Marine Sciences, 2(6) (2010), 532-538.

[6] D.V.C. Aweng, Ginger. Can. Pharm. J. 125 (1992) 309-311.

[7] W.H. Wang, Z.M. Wang, Studies on commonly used traditional medicine - ginger. Zhangguo Zhong Yao za Zhi, 30 (2005), $1569-1573$.

[8] I.C. Tapsell, I. Hemphill, I. Cobiac, et al. Health benefits of herbs and spices: The past, the present, the future. Med. J. Aust. 185(4) (2006), 424.

[9] M. Afzal, D. Al-Hadidi, M. Menem, J. Pesek, M.S. Dham, Ginger an ethnomedical chemical and pharmacological review. Drug metab. Drug Interact. 18 (2001), 159-190.

[10] S. Chrubasik, M.H. Pitter, B.D. Roufogalis, Zingiberis rhizoma: a comprehensive review on the ginger effect and efficacy profiles. Phytomedicine, 12 (2005), 684-701.

[11] E.L. Abubakar, Efficacy of crude extracts of garlic (Allium sativum Linn.) against nosocomial Escherichia coli, Staphylococcus aureus, Streptococcus pneumonia and Pseudomonas aeruginosa. Journal of Medicinal Plants research, 3 (2009), 179-185.

[12] S. Shobana, V.G. Vidhya, M. Ramya, Antibacterial activity of garlic varieties (ophioscordon and Sativum) on enteric pathogens. Current Research Journal of Biological Science, 1 (2009), 123 - 126.

[13] K. Rahman, Historical Perspective on Garlic and Cardiovascular Disease. The journal of nutrition, 131 (2001) 977-979.

[14] M. Steiner, W. Li, Aged Garlic Extract, a Modulator of Cardiovascular Risk Factors: A Dose-Finding Study on the Effects of AGE on Platelet Functions. The Journal of Nutrition, 131 (2001), 980-984.

[15] M.N. Indu, A.A. Hatha, C. Abinosh, U. Harsha, G. Vivekanandan, Antimicrobial activity of some South Indian spices against serotypes of Escherichia coli, Samonella, Listeria monocytogenes and Aeromonas Hydrophila. Brazilian Journal of Microbiology, 37 (2006), 153 - 158.

[16] WHO, Foodborne Disease Outbreak Guidelines. [Cit. 2012-11-27].http://www.who.int/foodsafety/publications/foodborne _disease/FERG_Nov07pdf (2007), date accessed June 23, 2013.

[17] A.B. Olayemi, F.I. Opaleye, Antibiotic resistance among coliform bacteria isolated from hospital and urban waste waters. World Journal of Microbiology, 6 (1999), 285-288.

[18] O. Arekemase, O. Kayode, E. Ajiboye, Antimicrobial Activity and phytochemical analysis of Jatropha curcas plant against some selected microorganisms. Inter. J. Biolo. 2011; 3(3) (2011), 52-55.

[19] A. Ohara, F. Saito, T. Matsuhisa, Screening of antibacterial activities of edible plants against Streptococcus mutans. Food Science and Technology Research, 14 (2008), 190-193.

[20] N.C.C. Silva, A. Fernandes Junior, Biological Properties of Medicinal Plants: A review of their antimicrobial activity. Journal of Venomous Animals and Toxins Including Tropical Disease, 16 (2010), 402-413.

[21] D. Daka, Antibacterial effect of garlic (Allium sativum) on Staphylococcus aureus: an in vitro study. African Journal of Biotechnology, 10 (2011), 666-669.

[22] V. Vuddhakul, P. Bhoopong, F. Hayeebilan, S. Sabhadhirasakul, Inhibitory activity of Thai condiments on pandemic strain of Vibrio parahaemolyticus. Food Microbiology, 24 (2007) 413-418.

[23] C. O. Esimone, C.F.B. Okoye, D.C. Odimegwu, C.S. Nworu, P.O. Oleghe, P.W. Ejogha, In vitro antimicrobial evaluation of lozenges containing extract of garlic and ginger. International Journal of Health Research, 3 (2010), 105-110.

[24] S. Nanasomabat, P. Lohasupthawee, Antibacterial activity of crude ethanolic extracts and essential oils of spices against salmonellae and other enterobacteria. KMITL Science and Technology Journal, 5 (2010), 527-538.

[25] M.M. Joe, J. Jayachitra, M. Vijaypriya, Antimicrobial activity of some common spices against certain human pathogens. Journal of medicinal Plants Research, 3 (2009), 1134-1136.

[26] R.V. Patel V.T. Thaker, V.K. Patel, Antimicrobial activity of ginger and honey on isolates of extracted carious teeth during orthodontic treatment, Asian Pacific Journal of Biomedicine, 1 (2011), S58-S61.

[27] S.A. Ibrahim, S.R. Dharamavaram, C.W. Seo, G. Shahbazi, Antimicrobial activity of Bifidobacterium Longum (CNCFB2259) as influenced by spices. Internet Journal of Food Safety, 2 (2003), 6-8.

[28] L.E.L. Sediek, W.M.M. Abozeid, D. H. Alkhalifah, S.E.A. FARAG, Efficacy of ginger extract (Zingiber officinale) and gamma irradiation for quality and self-stability of processed frozen beef sausage. Life Science Journal, 9 (2012), 448-461.

[29] O.C. Eruteya, S.A. Odunfa, Antimicrobial properties of three spices used in the preparation of suya condiment against organisms isolated from formulated samples and individual ingredients. African Journal of Biotechnology, 8 (2009), 2316-2320.

[30] G.O. Adeshina, S. Jibo, V.E. Agu, J.O. Ehinmidu, Antibacterial activity of fresh juices of Allium cepa and Zingiber officinale against multidrug resistant bacteria. International Journal of Pharma and Bio Sciences, 2 (2011), B289-B295. 